\title{
HOW TO MANAGE INTELLECTUAL CAPITAL CONFIGURATIONS TO IMPROVE FIRM PERFORMANCE IN THE INTERNET MEDICAL INDUSTRY
}

\author{
Xiaoya DAI ${ }^{\circledR}$, Weidong ZHU®, Chao ZHANG*, Yong WU, Xue HU \\ School of Management, HeFei University of Technoolgy, Hefei, China \\ Received 14 October 2020; accepted 14 June 2021; first published online 30 November 2021
}

\begin{abstract}
The internet medical industry is a new direction of the medical industry; however, internet medical enterprises have been going through a reshuffling period after 2016 and urgently need to improve their performance. The main aim of this study was to reveal the relationship between intellectual capital (IC) configurations and firm performance and guide ideal IC configuration decision to improve the performance of internet medical enterprises in China. First, a mechanism model was constructed to reveal the effects of IC configurations on firm performance, which is contribution to enrich IC configuration theory research. Then, fuzzy-set qualitative comparative analysis (fsQCA) was used to guide its IC configurations selection currently using data from internet medical enterprises in China from 2012 to 2019. The research is contribution to enrich application research of IC configuration. The results show that IC affects firm performance by means of the configuration; currently ideal IC configurations selection of the internet medical industry should pay attention to human, relationship and physical capital; period and specific business will both affect the choice of IC configuration. The results of this study can deepen managers' understanding of IC configurations and guide ideal IC configurations selection in the internet medical industry.
\end{abstract}

Keywords: IC, IC configuration, firm performance, mechanism model, fsQCA, internet medical industry.

JEL Classification: M41, C83, L20.

\section{Introduction}

The internet medical industry represents a new direction in the development of the medical industry. Especially during the influence of COVID-19 epidemic in 2020, the demand for internet medical treatment has become more urgent. The internet medical industry is conducive to optimizing the allocation and utilization of medical resources, facilitating the process of medical treatment, improving the efficiency of diagnostic consultations, reducing the imbalance of medical resources and inconvenience of face-to-face diagnosis. In 2016, the Chinese

\footnotetext{
${ }^{\star}$ Corresponding author. E-mail: zhang_chao_010@163.com
} 
government issued an outline of the "Healthy China 2030" plan, which first raised internet health care to the national strategic level. In the same year, the government promulgated policies and regulations, such as "Guidance on promoting and standardizing the application and development of health care big data", to strengthen the supervision of the internet medical industry. Consequently, this industry entered a reshuffling period, during which companies that could not develop rapidly and healthily were gradually eliminated. Thus, the internet medical enterprise is urgently needs to improve its firm performance (Han et al., 2020).

Intellectual capital (IC) plays an important role in internet medical industry and is of great significance to the development of the industry. Due to the progress of technology, economy and society gradually transition to the era of knowledge economy. In this era, IC as the representative of knowledge has changed the traditional way of value creation and become the most important source for promoting the development of enterprises (Urban \& Joubert, 2017; Ting et al., 2020). Positive relationship between IC and firm performance has already been affirmed in most researches especially for internet-based industry (Sydler et al., 2014; Xu \& Li, 2019; Salim \& Djausin, 2020). As a new type of internet-based industry formed by the deep integration of the internet, knowledge, information technology, traditional medical and health services, the development of internet medical industry is closely related to IC (Dženopoljac et al., 2016).

Ideal IC configurations are significant for improving firm performance of internet medical enterprises. Research shows that the improvement of firm performance is closely related to effective IC management (Guthrie et al., 2012). Optimized configurations make IC more effective at improving firm performance and that the collective effects of the configurations are more effective than any single component (Bayraktaroglu et al., 2019; Inkinen, 2015). Researches first focuses on single IC configuration, they concluded that specific IC configuration has an important impact on firm performance (Jardon \& Susana Martos, 2012). Then few have focuses on multiple IC configurations, they believed that ideal firm performance can be achieved through multiple IC configurations (Cricelli et al., 2018; Cabrillo \& Dahms, 2018). How to fully mobilize the components of IC and choose the ideal IC configurations is extremely important for improving firm performance especially in new industry with limited resource like the internet medical industry (Guthrie et al., 2012).

However, current research on the internet medical industry rarely pays attention to IC and its configurations which are very unfavorable to improving its firm performance. Faced with these problems and aiming to reveal the relationship between IC configurations and firm performance in the Chinese internet medical industry, this study formulated two research questions:

1. How does IC affect firm performance in the internet medical industry?

2. What are the ideal IC configurations that improve firm performance in the internet medical industry?

This study first took the internet medical industry as an example and constructed a mechanism model to reveal the IC configurations that affect firm performance theoretically. Then, the fuzzy-set qualitative comparative analysis (fsQCA) is choose to clarify the transformation of high-performance IC configurations before and after 2016 from empirical aspect to guide the selection of high-performance IC configurations of internet medical companies currently. 
This study makes the following contributions. To build the theoretical foundation of IC configuration research, a mechanism model is constructed to reveal effects of IC configurations on firm performance in the internet medical industry, which can enrich the theoretical research of IC configuration. Moreover, this study introduces IC configurations to the internet medical industry to meet the needs of improving corporate performance under limited resources of internet medical enterprises, which enriches IC literatures in internet medical industry from application level. The results of this study can deepen managers' understanding of the importance of IC configurations and guide them in selecting the ideal IC configurations that enhance firm performance in the internet medical industry.

The remainder of this paper is organized as follows. Section 1 contains a literature review of IC, firm performance and the internet medical industry. Section 2 presents the mechanism model of how IC configurations affect firm performance. Section 3 includes the research methods, the conditional and outcome variables. Section 4 presents the empirical results. Section 5 contains a discussion of the results and the last Section concludes the paper.

\section{Literature review}

\subsection{Definition and components of IC}

John Kenneth Galbraith first introduced the concept of IC in 1969. He believed that IC included both static knowledge and intellectual processes. Galbraith believed that the concept of IC should include human and organizational level. Then relationship levels is also incorporated into the concept of IC by Edvinsson (1997), who believed that IC should include professional knowledge, technical experience, professional skills, organizational technology, and customer relationships. Now, IC is considered to be all the knowledge, as well as the human capabilities, experiences, organizational structures, cultural atmosphere, and relationships with customers, suppliers, governments, etc., that can transform information into value and help firms create value to enhance their competitiveness (Johan \& Goran, 1997). However, there is no generally accepted definition of IC now.

Classifications of IC include two-component, three-component, and multi-component categorization. The two-component categorization divides IC into human capital (HC) and structural capital. HC refers to the part that can think actively while structural capital refers to the part that cannot think actively. The three-component categorization was proposed by Stewart and Ruckdeschel (1998), who further subdivided structural capital into organizational capital (OC) and relational capital (RC). The three-component categorization, which consists of $\mathrm{HC}, \mathrm{OC}$, and $\mathrm{RC}$, is the main approach approved by pioneering scholars (Tsui et al., 2014).

$\mathrm{HC}$ regards the intelligence of organizational members, including the features such as the knowledge, education, skills, abilities, attitudes, etc. that exist in the enterprise and cannot be replaced by machines (Joshi \& Sidhu, 2013). OC is the result and output contained in information technology systems and knowledge transformation and is composed of the employee support concepts, technical factors (such as information systems and databases), business operations paths, the corporate culture, intellectual assets (such as patents, copy- 
rights and trademarks), strategies, etc. that exist in the enterprise and are different from HC. It enables the inter participants of the company to collaborate and coordinate with each other (Tsui et al., 2014). RC refers to all knowledge acquired by organizations that can stimulate their value creation ability due to their interaction with the firms' external relations such as customers, suppliers, competitors, partners, the public, the government and other stakeholders (Edvinsson, 1997).

\subsection{IC and the internet medical industry}

IC is closely related to and plays an important role in the medical industry. Using data from the Italian medical industry, Carlucci and Schiuma (2012) explored the relationship between IC and the corporate environment. They pointed out that IC was of great significance to medical industry. The IC of an enterprise in the medical industry contains the skills of the members, professional levels, experience, internal operational abilities, and external relationships, which is the most valuable resource of medical enterprises (Pflugfelder, 2021).

IC is closely related to the firm performance of medical enterprises. Differing levels of firm performance can often be explained by the differing stocks of IC and by the abilities to use it. Huang et al. (2021) adopted a conceptual approach and concluded that IC is meaningful for the healthcare organizations to promote innovation and create value adopted a conceptual approach. Yang and Lin (2009) collected information on the medical industry in Taiwan to explore role of IC on firm performance and research showed that the higher the investment in IC, the better was the firm performance. Manes-Rossi et al. (2020) used questionnaires to explore managers' perceptions of IC in Italian local healthcare units and the interrelationships among the IC components. The results showed that IC affected the performances of the Italian local healthcare units while HC played a central role that linked the other IC components together.

However, there has been no research on IC, especially IC management, in the internet medical industry. Although the importance of IC to the performance of medical enterprises has been emphasized and the literature has been growing, the research has not advanced (Evans et al., 2015). As an emerging industry, IC plays an important role in the internet medical industry, however IC resources of the Internet medical industry are extremely scarce, and the reasonable configuration decision of IC under limited resources is particularly important (Dženopoljac et al., 2016). However, there are few clear and comprehensive suggestions for the management of IC configuration. This dearth is very unfavorable to improving, leveraging, and deploying IC to improve firm performance in the internet medical industry.

\section{Mechanism model of effects of IC configurations on firm performance in the internet medical industry}

This study constructed a mechanism model of the effects of IC configurations on firm performance in the internet medical industry. Through the mechanism model, the transformation process of IC to firm performance is deeply analyzed, and the configuration method of IC's effect on performance is verified. 


\subsection{Construction of mechanism model}

Strategic maps were introduced for the construction of the mechanism model of IC's effect on firm performance. Strategic maps is suitable to describe the process of transforming intangible knowledge assets, such as IC, into tangible financial results, such as firm performance, to describe and manage IC's value creation from financial, customer, internal process, learning and growth perspectives. When companies use strategic maps as investment and management tools, they can ensure that their activities are in line with corporate strategy ( $\mathrm{Wu}, 2005)$.

A mechanism model of the effects of IC configurations on firm performance in the internet medical industry was constructed according to the following process. IC components are invested into the learning and growth, internal process, customer perspective and interact with physical capital (PC). Then enterprises manage IC components under similar strategic theme and different strategic goals. Diversified strategic goals will cause different IC configuration decisions, which, in turn, affect firm performance. It is worth noting that, first, PC is the premise for the development and accumulation of IC, which in turn can improve the production capacity of PC (Murthy \& Mouritsen, 2011). Therefore, it is necessary to consider the synergy of PC when exploring the impact of IC on firm performance. Second, the strategic themes of the perspectives of all the enterprises are similarly based on Kaplan's strategic map template, but there are differences in strategic goals. Such differing strategic goals create difficulties to form a common template while IC management research concentrated on a small number of companies. This study drew on Kaplan's strategic map template to construct a universal framework for IC management and value creation analysis using the internet medical industry as an example, which is significant for IC management and the theoretical research on IC.

Figure 1 is the mechanism model based on a strategic map that illustrates the process of transforming IC into firm performance in the internet medical industry. According to the three-component categorization of IC, this article divides IC into HC, OC and RC. HC investment is reflected in the learning and growth perspective. OC investment is reflected in

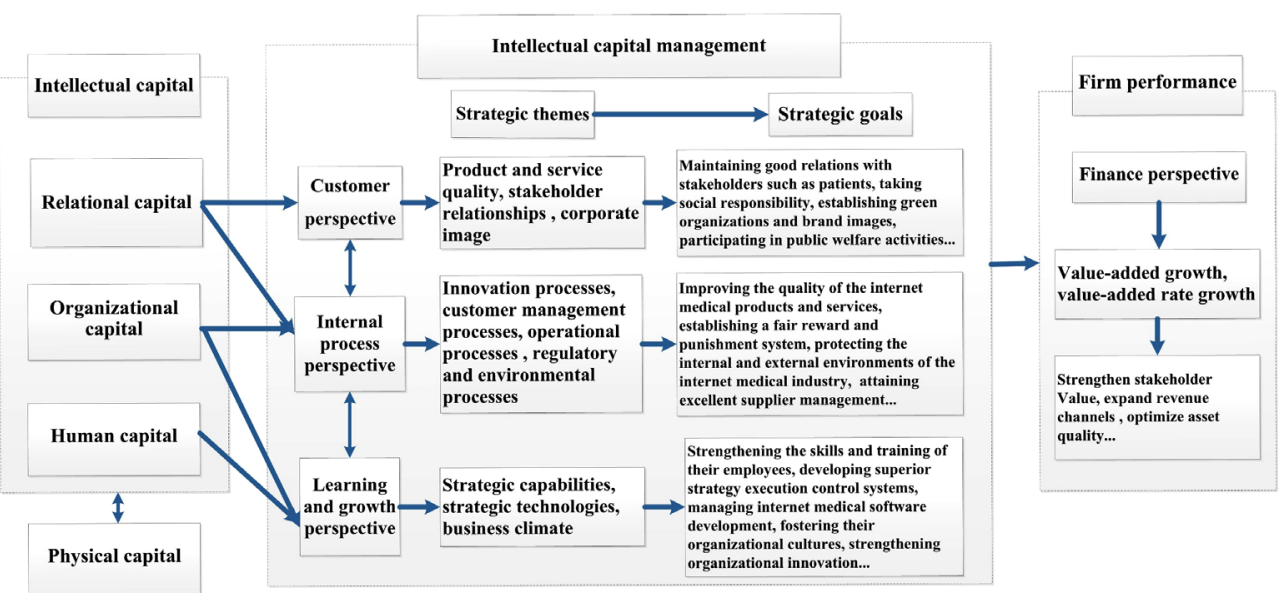

Figure 1. Mechanism model of effects of IC configurations on firm performance in the internet medical industry 
the learning and growth perspective and customer perspective. RC investment is reflected in the internal process and customer perspective. In addition to the above forms of capital, PC cannot be ignored when during the value creation process of IC because the elements of IC and PC are not separate from each other but interact and create value together.

The strategic themes of the learning and growth perspective include strategic capabilities, strategic technologies, and business climate. Strategic capabilities refer to the skills and knowledge of employees. Strategic technology refers to the information systems, databases, tools, and networks that are needed to support the implementation of strategies. Business climate refers to a culture that can mobilize employees and help them adapt to the needs of corporate strategy. Internet medical companies develop various strategic goals corresponding to these strategic themes, such as strengthening the skills and training of their employees, developing superior strategy execution control systems, managing internet medical software development, fostering their organizational cultures, and strengthening organizational innovation. Investments in the strategic capabilities of enterprises are regarded as $\mathrm{HC}$ while investments in strategic technology and business climate are regarded as OC (Kaplan \& Norton, 2010).

The strategic themes of internal operational perspectives include innovation processes, customer management processes, operational processes, regulatory processes, and environmental processes. Internet medical companies develop corresponding strategic goals such as improving the quality of the internet medical products and services, establishing a fair reward and punishment system, protecting the internal and external environments of the internet medical industry, and attaining excellent supplier management. Investments in the customer management process are regarded as RC. The inputs in innovation and customer management are regarded as OC (Kaplan \& Norton, 1996).

The customer perspective considers the important stakeholders of the firm. The strategic themes include product and service quality, corporate image, and relationships with stakeholders. Internet medical companies develop corresponding strategic goals, which include maintaining good relations with stakeholders such as patients, government and suppliers, taking social responsibility, establishing green organizations and brand images, and participating in public welfare activities. Investments related to these perspectives are regarded as relationship capital.

Various strategic goals of each enterprise will cause different IC configurations and finally affect firm performance. Previous studies have shown that strategy goal plays an important mediating role between capital structure and firm performance. Diversity strategy goals will affect capital structure, and then affect firm performance (Afza \& Ahmed, 2017). Although the strategic themes of internet medical enterprises at each perspective has similar characteristics, the strategic goals of them are diversified, which will lead to different IC management decisions on IC configurations. For example, based on the mechanism model proposed above, enterprises with the goal of strengthening organizational innovation of learning and growth perspective will focus on IC configuration that puts more resources into organizational capital. And enterprise holds the goal of attaining excellent supplier management of internal process perspective will chose IC configurations that focus on relational capital. Different IC configurations will cause different firm performance, which reflects the financial perspective produced by IC management. Its strategic themes are centered on value-added related indicators and corresponding strategic goals include strengthening value, expanding revenue channels and optimizing assets quality etc. 


\subsection{IC configuration and firm performance}

From the mechanism model, it can be seen that IC affects firm performance through configuration method. The mechanism model is based on the strategic map; the relationship between IC components in each perspective has characteristics similar to the relationship between each perspective of the strategic map. The four perspectives of the strategic map are a whole unified in a close logical relationship and mutually causal with interdependent, interrelated, and mutually influential characteristics. The internal operational perspective is the foundation, the customer perspective is the key points, the learning and growth perspective is the core, and the financial perspective is the ultimate goal. All the perspectives affect the results of the financial perspective through their combinations; thus, the configurations of the IC components in each perspective also affect the firm performance through configuration method.

The mechanism model theoretically confirms the effects of IC on firm performance through configuration method. This study used empirical methods to verify this from an empirical perspective and further explore those IC configurations that could achieve ideal firm performance of internet medical companies.

\section{Analysis method, conditional variables and outcome variables}

FsQCA was chosen as a tool for the empirical analysis of high-performance IC configurations. Drawing from the mechanism model, PC, HC, OC, and RC were selected as the conditional variables. Asset value-added rate was selected as the outcome variable.

\subsection{Analytical method: fuzzy-set qualitative comparative analysis (fsQCA)}

As the environment changes, there are many complex configuration relationships, such as nonlinear, non-independent, multiple causal, and asymmetric, between variables in reality. Management problems shifts from simple linear to configuration problems. Proposed in the 1980s by Ragin, qualitative comparative analysis (QCA) is on the basis of set theory and Boolean operations and combines the advantages of case-oriented research (qualitative) and variable-oriented research (quantitative) to solve configuration problems. The QCA method believes that the influence of a single element may be weak, different configurations may lead to the same result, and it explores multiple configurations based on asymmetric causality and antecedent complex data, hence, is more in line with the complex real world (Fiss, 2011). Traditional statistical analytical methods, such as regression analysis and structural equation modeling, focus more on correlation relationships are difficult for making comprehensive and reasonable explanations of complex configuration situations.

QCA can avoid the disadvantages of traditional statistical analytical methods, which have many requirements for data, such as sufficient sample size; independent, symmetric, and linear relationships between variables (Meuer \& Rupietta, 2017; Fiss, 2011). QCA has the following advantages: it can find multiple causal relationships between causes and results, signifying that multiple combinations of conditions can achieve the same result. Also, it can overcome not only the limits of data volume to handle large sample sizes for qualitative 
research or small sample sizes for quantitative research but also the linearity requirements of data to handle variables with diverse relationships. In addition, it can explore asymmetric relationships between causes and results. These characteristics are more in line with complex reality (Toth et al., 2017). Hence, QCA was chosen to address the problem of IC configuration. Besides, the fsQCA of QCA is used to study IC configuration which can handle with continuous variable.

Consistency and coverage are two important indicators in fsQCA. Consistency is for the judgment of sufficient conditions, in which a greater value represents a factor that is more likely to be a sufficient condition of the result. Coverage represents the explanatory power of the element, i.e., the degree of uniqueness that leads to uniform results. The greater the value, the stronger is the explanatory power.

$$
\begin{gathered}
\text { Consistency }:\left(X_{i} \leq Y_{i}\right)=\frac{\sum\left[\min \left(X_{i}, Y_{i}\right)\right]}{\sum X_{i}} ; \\
\text { Coverage }:\left(X_{i} \leq Y_{i}\right)=\frac{\sum\left[\min \left(X_{i}, Y_{i}\right)\right]}{\sum Y_{i}},
\end{gathered}
$$

where $X_{i}$ denotes the membership score of conditional variable, $Y_{i}$ denotes the Membership score of outcome variables.

\subsection{Conditional variables: IC components}

$\mathrm{HC}, \mathrm{OC}, \mathrm{RC}$, and PC, which exclude the influence of the enterprise scale, were chosen as the conditional variables to explore which high-performance IC configurations. These were selected according to the mechanism model. As the total value of capital investment would be affected by the size of an enterprise, these conditional variables are excluding the influence of the enterprise scale.

The VAIC model is used to calculate the components of IC. According to the VAIC model, the data of IC can be obtained directly from the financial statements. Thus it is more objective, fair, and also conducive to the comparison among enterprises, which is in line with the purpose of this paper to compare the differences between enterprises. Table 1 lists the calculations of the conditional variables (Xu \& Li, 2019).

Table 1. Calculations of conditional variables

\begin{tabular}{|c|l|}
\hline $\begin{array}{c}\text { Conditional } \\
\text { variables }\end{array}$ & \multicolumn{1}{c|}{ Calculation method } \\
\hline HC & $\begin{array}{l}\text { Cash paid to employees + Cash paid for employees + Difference between end and } \\
\text { beginning of payable period }\end{array}$ \\
\hline OC & Management expenses \\
\hline RC & Selling expenses \\
\hline PC & Book value of net assets \\
\hline
\end{tabular}

Note: $P C$ denotes the physical capital, $H C$ denotes the human capital, $O C$ denotes the organizational capital, and $R C$ denotes the relational capital. 


\subsection{Outcome variables: asset value-added rate}

The asset value-added rate is selected as an indicator of the outcome variable. Compared to profit indicators, the value-added indicator has many advantages. First, the value- added reflects all the wealth created by the enterprise, whereas the profit index reflects only the value attributed to shareholders. Therefore, the value-added indicator can provide more information to information users. Second, the value-added indicator as a measure of firm performance is beneficial for corporate value creation. Prior studies showed that value-added indicators could enhance corporate value more than could profit indicators. Therefore, after consideration of the effects of enterprise scale, the asset value-added rate was chosen as the indicator of firm performance (Chen et al., 2014).

The distribution method is choose as the basis for calculating the asset value-added rate. The method is more suitable for enterprise's afterwards summary and analysis, which is consistent with the research purpose of performance study in this paper. Table 2 lists the calculation method of the asset value-added rate (Yang \& Zhu, 2015).

Table 2. Calculation of asset value-added rate

\begin{tabular}{|l|l|}
\hline \multicolumn{1}{|c|}{ Indicators } & \multicolumn{1}{c|}{ Calculation method } \\
\hline Asset value-added rate & Value added / Year-end assets \\
\hline Value added & $\begin{array}{l}\text { Value added = Employee income + Government income + } \\
\text { Shareholder income + Creditor income + Enterprise income }\end{array}$ \\
\hline Employee income & $\begin{array}{l}\text { Cash Payments to and on behalf of Employees + Difference between end } \\
\text { and beginning of payable period }\end{array}$ \\
\hline Government income & $\begin{array}{l}\text { Payments of all types of taxes + Difference between end and beginning } \\
\text { of taxable period + Refunds of taxes }\end{array}$ \\
\hline Shareholder income & Shares in current year $\times$ Dividends per share \\
\hline Creditor income & Interest expenses \\
\hline Enterprise income & Net profit - Dividend pay-out \\
\hline
\end{tabular}

\section{Empirical results and analysis}

High-performance IC configurations is explored through empirical research, furthermore, period and specific business factors were discussed to more effectively guide the decisionmaking of IC configurations.

\subsection{Sample and data collection}

The selection of the internet medical enterprises were determined by the internet medical sector listed on Tonghuashun website, which is an authoritative Chinese stock website providing market display, analysis and trading data. The high-performance IC configurations of the internet medical industry before and after 2016 were compared to clarify the changes 
after 2016 and better guide internet medical corporations toward improving their firm performance and avoiding elimination from the market. The sample from 2016 to 2019 was treated as a sample after 2016, whereas that from 2012 to 2015 was treated as a sample before 2016. The data involved were taken from the China Stock Market \& Accounting Research Database (CSMAR). After abnormal data and missing indicators had been eliminated, the data before and after 2016 consisted of 269 and 293 pieces respectively.

\subsection{Data calibration}

All continuous variables need to be calibrated into fuzzy sets with values ranging from 0 to 1 first according to anchor points. A value of 1 represents full set membership, whereas 0 denotes no set membership. This study selected the upper quartile (75\%), the median (50\%), and the lower quartile (25\%) as the fully affiliated, intermediate and completely unaffiliated anchor points respectively, to calibrate the data (Ordanini et al., 2014). FsQCA 3.0 was applied for the automatic calibration and subsequent procedure. Table 3 list the variable calibration anchor points before and after 2016.

Table 3. Variable calibration anchor point before and after 2016

\begin{tabular}{|l|c|c|c|c|c|c|}
\hline \multirow{2}{*}{ Indicator } & \multicolumn{5}{|c|}{ Calibration anchor point } \\
\cline { 2 - 7 } & \multicolumn{3}{|c|}{ Before 2016 } & \multicolumn{3}{c|}{ After 2016 } \\
\cline { 2 - 7 } & CUP & IP & FAP & CUP & IP & FAP \\
\hline Asset value-added rate & 0.101 & 0.187 & 0.312 & 0.12 & 0.173 & 0.243 \\
\hline PC & 0.474 & 0.623 & 0.745 & 0.505 & 0.67 & 0.834 \\
\hline HC & 0.061 & 0.113 & 0.174 & 0.041 & 0.066 & 0.104 \\
\hline OC & 0.048 & 0.087 & 0.134 & 0.038 & 0.056 & 0.081 \\
\hline RC & 0.024 & 0.051 & 0.086 & 0.025 & 0.046 & 0.087 \\
\hline
\end{tabular}

Note: CUP denotes the completely unaffiliated point, IP denotes the intermediate point, FAP denotes the fully affiliated point, PC denotes the physical capital, HC denotes the human capital, OC denotes the organizational capital, and RC denotes the relational capital.

\subsection{Analysis of necessary conditions}

After calibration process, the conditional variables were analyzed for necessity. If the conditional variable was a necessary condition for the outcome variable, then it was a condition possessed by the result, but the appearance of the conditional variable did not necessarily cause the outcome variable to occur. When the threshold value of the consistency score of a conditional variable was greater than 0.9 (Ragin \& Fiss, 2008), the conditional variable was considered to be a necessary condition for the outcome variable. Table 4 lists the analysis of the necessary conditions before and after 2016. According to the results, no single conditional variable could be the necessary condition of the outcome variable before or after 2016. In other words, no single IC component could lead to firm performance. 
Table 4. Analysis of necessary conditions

\begin{tabular}{|l|c|c|c|c|c|c|c|c|c|}
\hline \multicolumn{2}{|c|}{ Conditional variable } & HC & $\sim \mathrm{HC}$ & OC & $\sim$ OC & RC & $\sim$ RC & PC & $\sim$ PC \\
\hline $\begin{array}{l}\text { Consis- } \\
\text { tency }\end{array}$ & Before 2016 & 0.492 & 0.66 & 0.466 & 0.695 & 0.724 & 0.443 & 0.724 & 0.385 \\
\cline { 2 - 10 } & After 2016 & 0.759 & 0.364 & 0.698 & 0.413 & 0.702 & 0.391 & 0.654 & 0.427 \\
\hline
\end{tabular}

Note: PC denotes the physical capital, HC denotes the human capital, OC denotes the organizational capital, RC denotes the relational capital, the wavy line $(\sim)$ denotes the opposite of condition exist. For instance, HC means high human capital investment, $\sim$ HC means low human capital investment.

\subsection{Results of high-performance IC configurations}

This study explores high-performance IC configurations before and after 2016 and makes some further analysis to more effectively guide the current decision-making of IC configurations.

\subsubsection{Results of IC configurations before 2016}

Table 5 lists the high-performance IC configurations in the Chinese internet medical industry before 2016. The black circles $(\bullet)$ denote the presence of a condition which could enhancement the asset value-added rate, while the crossed-out circles $(x)$ denote the absence of a condition, which will obstruct the realization of high asset value-added rate, and the blank spaces indicate "don't care".

Table 5. High-performance IC configurations before 2016

\begin{tabular}{|c|c|c|c|c|c|c|}
\hline IC & 1 & 2 & 3 & 4 & $\begin{array}{c}\text { Overall } \\
\text { consistency }\end{array}$ & $\begin{array}{c}\text { Overall } \\
\text { Coverage }\end{array}$ \\
\hline $\mathrm{HC}$ & $\bullet$ & $\bullet$ & & - & \multirow{6}{*}{0.803} & \multirow{6}{*}{0.59} \\
\hline $\mathrm{OC}$ & - & & - & - & & \\
\hline $\mathrm{RC}$ & & $\bullet$ & - & - & & \\
\hline $\mathrm{PC}$ & $x$ & $x$ & $x$ & & & \\
\hline Consistency & 0.813 & 0.851 & 0.848 & 0.804 & & \\
\hline Coverage & 0.302 & 0.274 & 0.278 & 0.447 & & \\
\hline
\end{tabular}

Note: PC denotes the physical capital, HC denotes the human capital, OC denotes the organizational capital, and RC denotes the relational capital.

All consistencies are above 0.8 , which are much higher than the accepted level of 0.75 (Foroudi et al., 2018). Therefore, these four configurations could be considered as combinations that realize high firm performance. The overall coverage is 0.59 , which indicates that these configurations cover about $59 \%$ of the cases and could be used to explain why most of the companies had achieved high firm performance.

1. $\mathrm{HC}^{\star} \mathrm{OC}^{\star} \sim \mathrm{PC}$

Configuration 1 indicates that a high firm performance could be reached with high HC and OC investments but without too many resources invested in PC. In addition, RC had little effect on firm performance. 
This causal combination has a very high value of consistency $(0.813)$, which means that the probability of achieving high firm performance with this IC configuration is $81.3 \%$. Moreover, the coverage of this configuration is 0.302 , which indicates that about $30.2 \%$ of the cases used this kind of IC configuration to obtain high firm performance.

\section{2. $\mathrm{HC}^{\star} \mathrm{RC}^{\star} \sim \mathrm{PC}$}

Configuration 2 indicates that a high firm performance could be reached with high $\mathrm{HC}$ and RC investments size but without too many resources invested in PC. In addition, OChad little effect on firm performance.

This causal combination has very high consistency $(0.851)$, which means that the probability of achieving high firm performance with this IC configuration is about $85.1 \%$. Moreover, the coverage of this configuration is 0.274 , which indicates that about $27.4 \%$ of the cases used this kind of IC configuration to obtain high firm performance.

\section{3. $\mathrm{OC}^{\star} \mathrm{RC}^{\star} \sim \mathrm{PC}$}

Configuration 3 indicates that a high firm performance could be reached with high OC and RC investments but without too many resources invested in PC. In addition, HC had little effect on firm performance.

This causal combination has a consistency of 0.848 , which means that the probability of achieving high firm performance with this IC configuration is $84.88 \%$. The coverage of this configuration is 0.278 , which indicates that about $27.8 \%$ of cases used this kind of IC configuration to obtain high firm performance.

\section{4. $\mathrm{HC}{ }^{\star} \mathrm{OC}^{\star} \mathrm{RC}$}

Configuration 4 indicates that a high firm performance could be reached with high HC, OC, and RC investments. PC had little effect on the firm performance.

This causal combination has a consistency of 0.804 , which means that the probability of achieving high firm performance with this IC configuration is $80.4 \%$. The coverage of this configuration is 0.447 , which indicates that about $44.7 \%$ of the cases used this kind of IC configuration to obtain high firm performance.

\subsubsection{Results of IC configurations after 2016}

Table 6 lists the high-performance IC configurations after 2016. As can be seen from Table 6, the consistencies and overall consistency are above 0.82 . Therefore, these three IC configurations can be considered as configurations for realizing high firm performance. The overall coverage is 0.736 , which indicates that the configuration covers about $73.61 \%$ of the cases and could be used to explain why most companies had achieved high firm performance.

\section{1. $\mathrm{HC}^{\star} \mathrm{RC}$}

Configuration 1 indicates that high firm performance could be reached with high HC and RC investments. OC and PC had little effect on firm performance.

This causal combination has very high consistency $(0.91)$, which means that the probability of achieving high firm performance with this IC configuration is $91 \%$. In addition, the 
coverage of this configuration is 0.555 , which indicates that about $55.5 \%$ of the cases used this kind of IC configuration to obtain high firm performance.

Table 6. High-performance IC configurations after 2016

\begin{tabular}{|c|c|c|c|c|c|}
\hline IC & 1 & 2 & 3 & $\begin{array}{c}\text { Overall } \\
\text { consistency }\end{array}$ & $\begin{array}{c}\text { Overall } \\
\text { Coverage }\end{array}$ \\
\hline $\mathrm{HC}$ & - & - & & \multirow{6}{*}{0.824} & \multirow{6}{*}{0.736} \\
\hline OC & & $x$ & - & & \\
\hline $\mathrm{RC}$ & - & & • & & \\
\hline $\mathrm{PC}$ & & - & • & & \\
\hline Consistency & 0.91 & 0.870 & 0.905 & & \\
\hline Coverage & 0.555 & 0.552 & 0.396 & & \\
\hline
\end{tabular}

Note: PC denotes the physical capital, HC denotes the human capital, OC denotes the organizational capital, and RC denotes the relational capital.

\section{2. $\mathrm{HC}^{\star} \sim \mathrm{OC}^{\star} \mathrm{PC}$}

Configuration 2 indicates that high firm performance could be reached with high $\mathrm{HC}$ and $\mathrm{PC}$ investments but without too many resources invested in $\mathrm{OC}$ and RC, which had little effect on firm performance.

This causal combination has a very high consistency $(0.87)$, which means that the probability of achieving high firm performance with this IC configuration is $87 \%$. In addition, the coverage of this configuration is 0.552 , which indicates that about $55.2 \%$ of the cases used this kind of IC configuration to obtain high firm performance.

\section{3. $\mathrm{OC}^{\star} \mathrm{RC} \mathrm{PC}^{\star} \mathrm{PC}$}

Configuration 3 indicates that a high firm performance could be reached through high OC, $\mathrm{RC}$, and PC investments. HC had little effect on the asset value-added rate.

This causal combination has a consistency of 0.905 , which means that the probability of achieving high firm performance with this IC configuration is $90.5 \%$. In addition, the coverage of this configuration is 0.396 , which indicates that about $39.6 \%$ of the cases used this kind of IC configuration to obtain high firm performance.

\subsubsection{Comparison of importance of IC configurations before and after 2016}

Table 7 lists the importance rankings of each IC component before and after 2016. Importance is ranked according to the hit frequencies of the IC components. A higher hit frequency indicated that the component is more important.

According to Table 7, the most important components for internet medical enterprises before 2016 were OC and HC. RC ranked third by only a slight gap. Meanwhile, PC was the least important. After 2016, the most significant components were HC and RC. The situations of OC and PC were quite different. Before 2016, PC was not important in any configuration, but, after 2016, it became the third most important component and appeared in two configurations. OC was one of the most important resources before 2016, but after 2016, it became the least important resource for the internet medical industry. 
Table 7. Importance rankings of IC components before and after 2016

\begin{tabular}{|l|c|c|c|c|c|}
\hline \multicolumn{3}{|c|}{ Before 2016 } & \multicolumn{3}{c|}{ After 2016 } \\
\hline $\begin{array}{c}\text { Conditional } \\
\text { variable }\end{array}$ & Hit frequency & $\begin{array}{c}\text { Importance } \\
\text { ranking }\end{array}$ & $\begin{array}{c}\text { Conditional } \\
\text { variable }\end{array}$ & Hit frequency & $\begin{array}{c}\text { Importance } \\
\text { ranking }\end{array}$ \\
\hline HC & 1.024 & 2 & HC & 1.107 & 1 \\
\hline OC & 1.028 & 1 & OC & 0.396 & 4 \\
\hline RC & 1 & 3 & RC & 0.951 & 2 \\
\hline PC & 0 & 4 & PC & 0.948 & 3 \\
\hline
\end{tabular}

Note: PC denotes the physical capital, HC denotes the human capital, OC denotes the organizational capital, and RC denotes the relational capital.

\subsubsection{Descriptive statistics analysis of high-performance IC configurations after 2016}

To propose more instructive suggestions of IC configuration and better understand the amount of IC components after 2016, a descriptive statistics was made of the components of the three high-performance IC configurations after 2016. Table 8 shows the descriptive statistics of the IC components of strong affiliated internet medical enterprise samples of each IC configuration after 2016.

Table 8. Descriptive statistics of IC components of high-performance IC configurations after 2016

\begin{tabular}{|c|l|c|c|c|}
\hline \multirow{2}{*}{ IC } & Descriptive statistics & $\mathrm{HC}^{\star} \mathrm{RC}$ & $\mathrm{HC}^{\star} \sim \mathrm{OC}^{\star} \mathrm{PC}$ & $\mathrm{OC}^{\star} \mathrm{RC}^{\star} \mathrm{PC}$ \\
\hline \multirow{4}{*}{$\mathrm{HC}$} & Average & 0.203 & 0.117 & 0.149 \\
\cline { 2 - 5 } & Minimum value & 0.13 & 0.082 & 0.007 \\
\cline { 2 - 5 } & Maximum value & 0.3 & 0.175 & 0.3 \\
\cline { 2 - 5 } & Standard deviation & 0.062 & 0.035 & 0.091 \\
\hline \multirow{5}{*}{ OC } & Average & 0.131 & 0.05 & 0.139 \\
\cline { 2 - 5 } & Minimum value & 0.05 & 0.042 & 0.073 \\
\cline { 2 - 5 } & Maximum value & 0.276 & 0.0562 & 0.276 \\
\cline { 2 - 5 } & Standard deviation & 0.08 & 0.005 & 0.071 \\
\hline \multirow{4}{*}{ RC } & Average & 0.217 & 0.043 & 0.145 \\
\cline { 2 - 5 } & Minimum value & 0.1 & 0.008 & 0.078 \\
\cline { 2 - 5 } & Maximum value & 0.356 & 0.096 & 0.35 \\
\cline { 2 - 5 } & Standard deviation & 0.094 & 0.035 & 0.064 \\
\hline \multirow{5}{*}{ PC } & Average & 0.717 & 0.754 & 0.821 \\
\cline { 2 - 5 } & Minimum value & 0.415 & 0.68 & 0.758 \\
\cline { 2 - 5 } & Maximum value & 0.876 & 0.85 & 0.04 \\
\cline { 2 - 5 } & Standard deviation & 0.153 & 0.062 & 0.877 \\
\hline
\end{tabular}

Note: PC denotes the physical capital, HC denotes the human capital, OC denotes the organizational capital, and RC denotes the relational capital.

The average value of $\mathrm{HC}$ input is the highest in the first configuration. The average value of $\mathrm{HC}$ investment in the third configuration is higher than that in the second configuration 
because the unbalanced investment, indicating that the amount of $\mathrm{HC}$ investment had no significant effect on the third configuration.

The average value of $\mathrm{OC}$ is the highest in the third configuration. In the second configuration, the average, standard deviation, maximum, and minimum values of OC are the lowest.

The average values of $\mathrm{RC}$ in the first and third configurations are higher than in the second configuration. In addition, the value in the first configuration is higher than that in the third configuration, indicating that when there are few types of IC investment, the single capital investment should be increased.

The importance of PC is reflected in the second and third configurations. The average values of $\mathrm{PC}$ are also higher in these two configurations. Meanwhile, the highest standard deviation of $\mathrm{PC}$ in the first configuration reflects the imbalance and unimportance of PC investment and the unimportance of PC.

\subsubsection{Specific businesses analysis of high-performance IC configurations after 2016}

This paper argues that there may be differences in high-performance IC configurations due to specific businesses internet medical enterprises are engaged in. Thus, to deeply analyze the influence of specific businesses on the choice of high-performance IC configurations, this study further discusses specific businesses of strongly affiliated internet medical enterprises in which these three high-performance IC configurations were engaged in. Table 9 lists the number of internet medical enterprises in each IC configuration for specific businesses.

Table 9. Number of internet medical enterprises in each IC configuration for specific businesses

\begin{tabular}{|l|c|c|c|c|}
\hline \multicolumn{1}{|c|}{ Specific business } & $\begin{array}{c}\text { No. of } \\
\text { enterprises }\end{array}$ & $\mathrm{HC} C^{\star} \mathrm{RC}$ & $\mathrm{HC} C^{*} \sim \mathrm{OC}^{\star} \mathrm{PC}$ & $\mathrm{OC}{ }^{*} \mathrm{RC} \mathrm{PC}^{\star}$ \\
\hline Manufacturing & 149 & 6 & 3 & 16 \\
\hline Wholesale and retail trade & 32 & 4 & 0 & 0 \\
\hline Information technology and software & 99 & 9 & 3 & 4 \\
\hline Health & 10 & 1 & 0 & 0 \\
\hline Publishing & 2 & 0 & 1 & 0 \\
\hline Total & 293 & 20 & 10 & 20 \\
\hline
\end{tabular}

There are five kinds of businesses in which internet medical enterprises are engaged: manufacturing, retail and wholesale, information technology and software, health, and publishing. Overall, the number of manufacturing enterprises is the highest, accounting for about half of the total. According to the strongly affiliated samples, the high-performance IC configurations most commonly used by the manufacturing enterprises are ' $\mathrm{C}^{\star} \mathrm{RC}{ }^{\star} \mathrm{PC}$ ', typical enterprises such as Xiangshan Co., Ltd. and Rongjie Health Co. are engaged in instrument and machinery manufacturing. The ' $\mathrm{HC}{ }^{\star} \mathrm{RC}$ ' have been adopted by the lowest number of manufacturing companies, its typical enterprise is Business Win Global Co., which belongs to the textile and apparel industry. For the configuration of ' $\mathrm{HC}{ }^{\star} \sim \mathrm{OC}^{\star} \mathrm{PC}$ ', a typical enterprise is Fenda Technology Co., which belongs to computer communications and other electronic equipment manufacturing. 
The second-highest numbers of companies are engaged in the information technology and software industries. It is noteworthy that most companies engaged in this industry had chosen ' $H C^{\star} R C$ '. Whereas some specific sub-businesses, for example, companies engaged in telecommunications, radio, television, satellite transmission services, and internet-related services chose others, typical enterprises are Yitong Century Co. and People’s Daily Online Co. All typical samples of the wholesale and retail businesses adopted ' $\mathrm{HC}{ }^{\star} \mathrm{RC}$ '. The only typical sample of health and publishing enterprise adopted ' $\mathrm{HC}{ }^{\star} \mathrm{RC}$ ' and ' $\mathrm{HC}{ }^{\star} \mathrm{PC}$ ' respectively.

\section{Discussion}

The aforementioned results are multifaceted and deserve a focussed discussion. Results of this study proved that IC has an effect on firm performance through configuration method, in line with previous studies (Agostini \& Nosella, 2017). The theoretical analysis construct a mechanism model of effects of IC configurations on firm performance in the internet medical industry and verified that the effects of IC components had been due to configuration method through synergy effect relationship of each perspective. Besides, the empirical study further complements the result of the theoretical analysis. The empirical research also shows that no single IC component could affect firm performance, each component had to be combined with another to affect firm performance through configuration method, and multiple IC configurations can achieve the same firm performance (Cricelli et al., 2018; Cabrillo \& Dahms, 2018). Therefore, in the process of improving firm performance, managers should fully consider IC configuration rather than single IC components, and they should choose ideal IC configurations to allocate IC components according to firm strategies.

Furthermore, we have further demonstrated that an advanced, broader perspective, admitting that the choice of IC configuration will be affected by period and specific businesses compared to previous studies. First, the effects of IC configurations on firm performance varied during different periods. Having compared the ideal IC configurations before and after 2016, this study found that there are significant differences in the IC configurations, which play a key role in firm performance improvement of different period. For instance, OC was the most important capital, but after 2016, it became the least important. This may be due to the change of IC concerns caused by policy changes in different periods. Second, Having compared the ideal IC configurations of firm engaged in specific businesses this study find that the effects of IC configuration on firm performance varied according to specific businesses. For instance, most companies engaged in software and information technology services had chosen the ' $\mathrm{HC}{ }^{\star} \mathrm{RC}$ ' configuration, whereas all internet-related service companies had chosen the ' $\mathrm{HC}^{\star} \sim \mathrm{OC}^{\star} \mathrm{PC}$ ' configuration. Therefore, time and industry factors should be fully considered when making IC configuration decisions.

\section{Conclusions}

The vigorous development and the increasingly strict supervision of the internet medical industry require the selection of ideal IC configurations so that enterprises can prevent defeat by competitors and elimination from the industry. The choice of the ideal IC configuration 
is of great significance to the improvement of firm performance and to the maintenance of the competitiveness of internet medical companies. However, existing studies have neglected the importance of IC and its configurations in the internet medical industry.

This study examined the relationship between IC configuration and firm performance of the internet medical industry. First, a mechanism model of the effects of IC configuration on firm performance of internet medical industry was constructed. Then, fsQCA was chosen to explore high-performance IC configurations of internet medical industry before and after 2016 to guide the selection of ideal IC configurations.

This study contribution to constructs the theoretical basis of IC configuration research through the mechanism model, which meaningful for enriching the research theory of IC configuration. Besides, this study introduces IC configurations to the internet medical industry to meet the needs of improving corporate performance under limited resources of internet medical enterprises, which enriches IC literatures in internet medical industry from application level.

The results of this study can deepen managers' understanding of the importance of IC configurations and offer guidance on decisions about ideal IC configurations. First, the results enable managers to understand that IC needs to affect firm performance through configuration method. Therefore, the improvement of firm performance should not rely on investments in a single component of IC but should integrate and use the various combinations of IC components. Second, the results can provide a reference for managerial decision-making about which IC configurations could best improve firm performance. In addition, the results of the empirical analysis illustrate the difference in high-performance IC configurations of different period and specific business, so that managers can pay attention to these difference, and take them into full consideration when making decisions on IC configuration.

Some limitations of this study are noted. In light of the recent global pandemic, the internet medical industry has been changing since 2019. The role of IC during the global pandemic may also change. However, the study was able to use only the data available by the end of 2019. In addition, the effects of capital on enterprises are long-term and continuous processes. This study observed only the conditions of IC in the internet medical industry from 2012 to the end of 2019. Therefore, Future research will continue to observe the role of IC in the internet medical industry and study IC in the internet medical industry from a long-term perspective.

\section{Acknowledgements}

The authors ensure that anyone named in the acknowledgments agrees to being named.

\section{Funding}

This work was supported by the $<$ National Natural Science Foundation of China \# $1>$ under Grant [number 71774047]; < Research on Humanities and social sciences of the Ministry of Education \#2> under Grant [number 20YJC630203]; and < Project of Natural Science Foundation of Anhui Province \#3> under Grant [number 2008085QC340]. 


\section{Author contributions}

$\mathrm{XD}$ was responsible for data collection and analysis. WZ and RW were responsible for supervision. XD and YT conceived the study and were responsible for the design and development of the data analysis. C.Z was responsible for review and editing. $\mathrm{XD}$ and $\mathrm{WZ}$ were responsible for data collection and analysis. XD and $\mathrm{WZ}$ were responsible for data interpretation. XD wrote the first draft of the article.

\section{Disclosure statement}

The authors declare no conflict of interest.

\section{References}

Agostini, L., \& Nosella, A. (2017). Enhancing radical innovation performance through intellectual capital components. Journal of Intellectual Capital, 18(4), 789-806. https://doi.org/10.1108/JIC-10-2016-0103

Afza, T., \& Ahmed, N. (2017). Capital structure, business strategy and firm's performance: Evidence from Pakistan. European Online Journal of Natural and Social Sciences, 6(2), 302-328. https://core.ac.uk/reader/230041910

Bayraktaroglu, A. E., Calisir, F., \& Baskak, M. (2019). IC and firm performance: an extended VAIC model. Journal of Intellectual Capital, 20(3), 406-425. https://doi.org/10.1108/JIC-12-2017-0184

Cabrilo, S., \& Dahms, S. (2018). How strategic knowledge management drives IC to superior innovation and market performance. Journal of Knowledge Management, 22(3), 621-648. https://doi.org/10.1108/JKM-07-2017-0309

Carlucci, D., \& Schiuma, G. (2012). Assessing and managing organizational climate in healthcare organizations: An IC based perspective. International Journal of Information Systems in the Service Sector (IJISSS), 4(4), 49-61. https://doi.org/10.4018/jisss.2012100103

Chen, J., Jiang, C., \& Lin, Y. (2014) What determine firms' capital structure in China? Managerial Finance, 40(10), 1024-1039. https://doi.org/10.1108/MF-06-2013-0163

Cricelli, L., Greco, M., Grimaldi, M., \& Llanes Duenas, L. P. (2018). IC and university performance in emerging countries: Evidence from Colombian public universities. Journal of Intellectual Capital, 19(1), 71-95. https://doi.org/10.1108/JIC-02-2017-0037

Dženopoljac, V., Janoševic, S., \& Bontis, N. (2016). Intellectual capital and financial performance in the Serbian ICT industry. Journal of Intellectual Capital, 17(2), 373-396. https://doi.org/10.1108/JIC-07-2015-0068

Edvinsson, L. (1997). Developing IC at Skandia. Long Range Planning, 30(3), 366-373. https://doi.org/10.1016/S0024-6301(97)90248-X

Evans, J. M., Brown, A., \& Baker, G. R. (2015). Intellectual capital in the healthcare sector: A systematic review and critique of the literature. BMC Health Services Research, 15(1), 556. https://doi.org/10.1186/s12913-015-1234-0

Fiss, P. C. (2011). Building better causal theories: A fuzzy set approach to typologies in organization research. Academy of Management Journal, 54(2), 393-420. https://doi.org/10.5465/amj.2011.60263120

Foroudi, P., Jin, Z., Gupta, S., Foroudi, M. M., \& Kitchen, P. J. (2018). Perceptional components of brand equity: Configuring the Symmetrical and Asymmetrical Paths to brand loyalty and brand purchase intention. Journal of Business Research, 89(1), 462-474. https://doi.org/10.1016/j.jbusres.2018.01.031 
Guthrie, J., Ricceri, F., \& Dumay, J. (2012). Reflections and projections: A decade of IC accounting research. The British Accounting Review, 44(2), 68-82. https://doi.org/10.1016/j.bar.2012.03.004

Han, J., Zhang, X., \& Meng, Y. (2020). The impact of internet medical information overflow on residents' medical expenditure based on China's observations. International Journal of Environmental Research and Public Health, 17(10), 3539. https://doi.org/10.3390/ijerph17103539

Huang, H., Leone, D., Caporuscio, A., \& Kraus, S. (2021). Managing IC in healthcare organizations. A conceptual proposal to promote innovation. Journal of Intellectual Capital, 22(2), 290-310. https://doi.org/10.1108/JIC-02-2020-0063

Inkinen, H. (2015). Review of empirical research on IC and firm performance. Journal of Intellectual Capital, 16(3), 518-565. https://doi.org/10.1108/JIC-01-2015-0002

Jardon, C. M., \& Susana Martos, M. (2012). IC as competitive advantage in emerging clusters in Latin America. Journal of Intellectual Capital, 13(4), 462-481. https://doi.org/10.1108/14691931211276098

Johan, R., \& Goran, R. (1997). Measuring your company's intellectual performance. Long Range Planning, 30(3), 413-426. https://doi.org/10.1016/S0024-6301(97)90260-0

Joshi M, C. D., \& Sidhu, J. (2013). IC and financial performance: An evolution of the Australian financial sector. Journal of Intellectual Capital, 14(2), 264-285. https://doi.org/10.1108/14691931311323887

Kaplan, R. S., \& Norton, D. P. (1996). The balanced scorecard. Technometrics, 40(3), 266-266. https://doi.org/10.1080/00401706.1998.10485544

Kaplan, R. S., \& Norton, D. P. (2010). The strategy-focused organization: How balanced scorecard companies thrive in the new business environment ( $\left.3^{\text {rd }} \mathrm{ed}\right)$. Harvard Business School Publishing Corporation.

Manes-Rossi, F., Bisogno, M., Aversano, N., \& Citro, F. (2020). IC in Italian healthcare: Senior managers' perspectives. International Journal of Public Sector Management, 33(6/7), 629-646. https://doi.org/10.1108/IJPSM-11-2019-0298

Meuer, J., \& Rupietta, C. (2017). A review of integrated QCA and statistical analyses. Quality \& Quantity, 51(5), 2063-2083. https://doi.org/10.1007/s11135-016-0397-Z

Murthy, V., \& Mouritsen, J. (2011). The performance of intellectual capital: Mobilising relationships between intellectual and financial capital in a bank. Accounting, Auditing \& Accountability Journal, 24(5), 622-646. https://doi.org/10.1108/09513571111139120

Ordanini, A., Parasuraman, A., \& Rubera, G. (2014). When the recipe is more important than the ingredients: A qualitative comparative analysis (QCA) of service innovation configurations. Journal of Service Research, 17(2), 134-149. https://doi.org/10.1177/1094670513513337

Pflugfelder, N. S. (2021). Knowledge management as a driver of performance in ambulatory healthcare - a systematic literature review through an intellectual capital lens. Journal of Intellectual Capital, 22(2), 403-432. https://doi.org/10.1108/JIC-02-2020-0068

Ragin, C. C., \& Fiss, P. C. (2008). Redesigning social inquiry: Fuzzy sets and beyond (11 $1^{\text {th }} \mathrm{ed)}$. University of Chicago Press. https://doi.org/10.7208/chicago/9780226702797.001.0001

Salim, M. N., \& Djausin, R. P. I. (2020). Determinants of financial performance and its impact on the growth of Islamic Bank Assets on Indonesia. International Journal of Business, Economics and Management, 7(1), 27-41. https://doi.org/10.18488/journal.62.2020.71.27.41

Stewart, T., \& Ruckdeschel, C. (1998). IC: The new wealth of organizations. Performance Improvement, 37(7), 56-59. https://doi.org/10.1002/pfi.4140370713

Sydler, R., Haefliger, S., \& Pruksa, R. (2014). Measuring IC with financial figures: Can we predict firm profitability? European Management Journal, 32(2), 244-259.

https://doi.org/10.1016/j.emj.2013.01.008

Ting, I. W. K., Ren, C., Chen, F. C., \& Kweh, Q. L. (2020), Interpreting the dynamic performance effect of IC through a value-added-based perspective. Journal of Intellectual Capital, 21(3), 381-401. https://doi.org/10.1108/JIC-05-2019-0098 
Toth, Z., Henneberg, S. C., \& Naude, P. (2017). Addressing the "Qualitative" in fuzzy set Qualitative Comparative Analysis: The generic membership evaluation template. Industrial Marketing Management, 63, 192-204. https://doi.org/10.1016/j.indmarman.2016.10.008

Tsui, E., Wang, W. M., Cai, L., Cheung, C., \& Lee, W. (2014). Knowledge-based extraction of IC-related information from unstructured data. Expert Systems with Applications, 41(4), 1315-1325. https://doi.org/10.1016/j.eswa.2013.08.029

Urban, B., \& Joubert, G. C. D. S. (2017). Multidimensional and comparative study on IC and organisational performance. Journal of Business Economics and Management, 18(1), 84-99. https://doi.org/10.3846/16111699.2016.1255990

$\mathrm{Wu}, \mathrm{A}$. (2005). The integration between balanced scorecard and IC. Journal of Intellectual Capital, 6(2), 267-284. https://doi.org/10.1108/14691930510592843.

$\mathrm{Xu}$, J., \& Li, J. (2019). The impact of IC on SMEs' performance in China: Empirical evidence from nonhigh-tech vs. high-tech SMEs. Journal of Intellectual Capital, 20(4), 488-509. https://doi.org/10.1108/JIC-04-2018-0074

Yang, C. C., \& Lin, Y. Y. (2009). Does IC mediate the relationship between HRM and organizational performance? Perspective of a healthcare industry in Taiwan. International Journal of Human Resource Management, 20(9), 1965-1984. https://doi.org/10.1080/09585190903142415

Yang, C. C., \& Zhu, W. D. (2015). Added value distribution pattern and its determinant factors analysisempirical study based on our country listed company. Chinese Journal of Management Science, 23(03), 141-150. https://doi.org/10.16381/j.cnki.issn1003-207x.2015.03.017 